Revista PSICOLOGIA, 2020, Vol. 34 (2), 57-74. doi: 10.17575/psicologia.v34i2.1385

\title{
Preconceito racial em crianças: Identificação e pertença grupal
}

\author{
Joana Carlos $^{1} \&$ Madalena Melo ${ }^{1,2}$ \\ ${ }^{1}$ Departamento de Psicologia - Universidade de Évora \\ ${ }^{2}$ CIDEHUS - Centro Interdisciplinar de História, Culturas e Sociedades - Universidade de Évora
}

\begin{abstract}
Resumo: De acordo com a Teoria da Identidade Social, basta tornar saliente a pertença de um indivíduo a uma categoria/grupo social para que existam enviesamentos endogrupais e discriminação face a membros de outros grupos. 0 presente estudo procurou analisar a existência de diferenças no preconceito racial (face a negros, mulatos e brancos) em função da identidade étnica (autocategorização e avaliação emocional da pertença), bem como a relação existente com as variáveis contacto interétnico e distância social. Participaram neste estudo 258 crianças do 2.ำ ciclo de 4 escolas públicas portuguesas, que se autocategorizaram como brancas e mulatas. Os principais resultados parecem indicar que o preconceito subtil é diferente consoante o nível da componente afetiva da identidade étnica, que o contacto interétnico se relaciona com menores níveis de preconceito subtil e flagrante e que existem diferenças no contacto interétnico e distância social por grupo de autocategorização.
\end{abstract}

\section{Palavras-chave: Grupos étnicos/raciais; pertença grupal; preconceito; contacto interétnico.}

Racial prejudice in children: Group identification and group membership: According to Social Identity Theory emphasizing the belonging of an individual to a category / social group it is enough to foster ingroup bias and discrimination against members of other groups. The present study aims to analyze the differences between racial prejudice (against black, mulatto and white) according to ethnic identity (in terms of selfcategorization and emotional evaluations of belonging) and also it's relation with the interethnic contact and social distance variables. A total of 258 children from 5 th and 6 th grades of 4 Portuguese public schools, selfcategorizated as white or mulatto, participated in the study. The main results seem to suggest that subtle prejudice is different depending on the level of the affective component of ethnic identity, interethnic contact relates to lower levels of subtle and blatant prejudice, and that there are differences in interethnic contact and social distance per group of selfcategorization.

\section{Keywords:. Ethnic/racial groups; group membership; prejudice; interethnic contact.}

A discriminação com base na origem étnica é considerada a forma mais comum de discriminação na União Europeia (64\%) de acordo com dados do Eurobarómetro de 2015.0 preconceito e a discriminação têm-se tornado cada vez mais invisíveis devido à pressão da norma antirracista contra grupos minoritários, tomando atualmente formas de expressão mais subtis e indiretas (França \& Monteiro, 2013). Embora as formas mais tradicionais de racismo sejam menos frequentes, ainda existem e, tal como as formas mais subtis, têm consequências negativas para quem é alvo do mesmo (Lima \& Vala, 2004).

É importante o estudo precoce destes fenómenos visto que, apesar de existir um contexto educativo com discurso antirracista, continua-se a assistir a atos de violência racista por parte das crianças/jovens e, por outro lado, a investigação sugere que crianças preconceituosas têm mais probabilidade de se tornarem adultos preconceituosos (Abrams \& Killen, 2014).

\section{Identidade social e enviesamentos intergrupais}

A identidade social pode ser definida como a parte do autoconceito que advém da pertença a grupo(s) que são relevante(s), juntamente com o valor emocional associado a essa pertença (Tajfel, 1982). Apesar de muitos teóricos considerarem a multidimensionalidade do constructo, não existe consenso quanto ao número e à natureza de dimensões relativamente à identidade étnica. No entanto importa destacar dois elementos: a autocategorização que, enquanto conhecimento por parte do indivíduo da sua pertença a um grupo (étnico) (França \& Monteiro, 2002), é considerada o elemento base da identidade grupal (Ashmore et al., 2004), e a avaliação emocional da pertença que, de acordo com Tajfel (1974), é a dimensão mais importante do constructo.

1 Morada para correspondência: Madalena Melo, Departamento de Psicologia da Universidade de Évora. Colégio Pedro da Fonseca. Apartado 94. 7002554 Évora. Portugal. E-mail: mmm@uevora.pt 
A identidade social constrói-se através de comparações com outros grupos relevantes, de modo a permitir uma distintividade positiva do endogrupo. Esta necessidade de distintividade positiva motiva então comparações sociais que diferenciem de forma favorável o endogrupo do exogrupo, o que leva muitas vezes a uma tendência para comparações entre grupos enviesadas (Tajfel \& Turner, 1986).

A mera categorização social, nomeadamente a distinção entre endogrupo e exogrupo, demonstra-se então, em certas circunstâncias, como condição mínima para a emergência de enviesamento endogrupal (Vala \& Costa-Lopes, 2016). Diversos estudos com base no paradigma do grupo mínimo de Tajfel e colaboradores (Nesdale et al., 2010), com diversos critérios para a divisão dos participantes, mostraram os mesmos resultados: o simples facto de ser informado de que está num grupo com outras pessoas muda a forma como se pensa sobre os outros. 0 mesmo se passa com as crianças: a mera atribuição de um grupo à criança aumenta o gosto pelos membros do endogrupo em comparação com os pertencentes a outros grupos (Nesdale et al., 2004).

A identidade grupal, embora importante e necessária ao bem-estar psicológico e funcionamento efetivo da sociedade, tem, de acordo com a Teoria da Identidade Social (TIS), o potencial de contribuir para o preconceito através de julgamentos negativos face a membros de outros grupos (Killen \& Rutland, 2011). Se as ameaças à distintividade positiva são suficientemente severas, as tentativas de diferenciar o endogrupo do exogrupo podem evoluir de expressões suaves de enviesamento, a atitudes abertamente depreciativas, ou seja, preconceito (Brown, 2010).

Desta forma, a identidade de grupo pode ser vista como um aspeto positivo ou negativo para o desenvolvimento social das crianças. Os aspetos negativos surgem quando uma forte identidade grupal é utilizada para criar níveis de estatuto e normas grupais promotoras de exclusão. Essa identificação com o grupo pode resultar no desejo de tornar o grupo único, diferente e superior a outros grupos pela adesão a estereótipos negativos para o alcançar (Killen \& Rutland, 2011).

\section{Estudos sobre Identidade Étnica}

A identidade étnica tem sido estudada tendo em conta o seu papel na perceção de variabilidade do exogrupo e na avaliação dos grupos (Guinote et al., 2007).

As crianças são desde muito cedo orientadas para o endogrupo étnico (Nesdale, 2000). Estudos com grupos maioritários (Nesdale et al., 2004) mostram que gostam mais do endogrupo do que do exogrupo; essa preferência, que pode ser diferente consoante os grupos presentes, fornece o contexto a partir do qual os membros de exogrupo(s) são julgados (Nesdale, 2000). Apesar da evidência de que as crianças favorecem o seu grupo, esta não se relaciona necessariamente com visões negativas do exogrupo (Bennett et al., 2004), rejeição ou expressão aversiva de preconceito face a membros de outros grupos (Nesdale, 2000).

Como se pode verificar na revisão de Gautier (2016), a maioria dos estudos sobre identidade étnica relaciona-se com a discriminação percecionada e o bem-estar psicológico em membros de minorias étnicas. Neste âmbito, a investigação foca-se nos grupos minoritários de modo a compreender as consequências ou os efeitos da discriminação percecionada e também quais as variáveis que podem servir como proteção ou risco (Alamilla et al., 2017). A identidade étnica, neste sentido, é vista como um fator protetor que se relaciona com um menor efeito do preconceito e estereótipos (Stangor, 2016).

Quanto ao preconceito do próprio face aos outros, que se relaciona com a presente investigação, Bano e Mishra (2014) verificaram uma relação positiva entre identidade social e preconceito em grupos maioritários e minoritários, o que sugere que os grupos tendem a ter uma grande admiração pela sua identidade social e que essa confiança se liga ao own group glorification, que pode ter como resultado formas subtis de preconceito.

\section{Preconceito racial}

O preconceito pode ser definido como uma atitude negativa face a um grupo ou aos seus membros (Stangor, 2016). Apesar de nem todo o preconceito levar a ações discriminatórias, este pode ser visto como um processo que alimenta a discriminação e o racismo.

0 preconceito étnico é uma forma específica de preconceito que se caracteriza por atitudes negativas face a outros grupos étnicos, sendo este o foco do presente estudo. Os aspetos que definem os grupos étnicos são variados e podem incluir a linguagem, religião, práticas culturais, local de nascimento e/ou cor da pele. Quando um grupo étnico é definido, pelo menos em parte, pela cor da pele, também pode ser referenciado como grupo racial (Keenan et al., 2016) ${ }^{2}$.

2 Embora raça seja uma vertente distinta de etnia, ao longo deste trabalho utiliza-se a expressão "grupo racial" sempre que se refere à distinção pela cor da pele. 
A expressão de formas clássicas de discriminação racial na sociedade contemporânea tem diminuído (França \& Monteiro, 2013). Após a 2ª Guerra Mundial houve uma enorme mudança na forma de expressão do preconceito devido a pressões da legislação antirracista e dos princípios da igualdade que tornaram saliente a presença da norma antirracista contra grupos minoritários (França \& Monteiro, 2013; Lima \& Vala, 2004), tendo-se esta tornado progressivamente mais subtil, indireta e menos "abertamente" negativa (França \& Monteiro, 2004; 2013).

\section{Estudos sobre Preconceito Racial}

Uma grande parte dos estudos realizados com crianças, tanto internacionais (Dore et al., 2014) como portugueses (Egito, 2013), centram-se nos vieses psicológicos, nomeadamente o favoritismo do endogrupo (Rodrigues et al., 2010) que se pode refletir na preferência racial (Máximo et al., 2012).

Relativamente ao preconceito racial e enviesamentos intergrupais, um número considerável de investigações foca-se nos grupos maioritários face à cor da pele ou nacionalidade. Tendo em conta os estudos com foco na cor da pele, esta é considerada de variadas formas: tendo por base a autocategorização das crianças (Alexandre et al., 2007; Egito, 2013); por consenso de juízes (Máximo et al., 2012); por categorização dos pais (Dore et al., 2014); nos casos em que se inclui apenas o grupo maioritário, por vezes não são referidos os critérios quando o foco é a etnia/cor da pele (Castelli \& Tomelleri, 2008; Monteiro et al., 2009).

As várias investigações relacionadas com as normas sociais demonstram que a idade é uma variável importante, não apenas por haver uma diminuição dos vieses, mas porque com a idade a expressão do preconceito pode ser melhor autorregulada de acordo com os diferentes níveis de pressão social presentes no contexto (Monteiro et al., 2009).

A meta-análise de Raabe e Beelman (2011) demonstra um decréscimo na expressão do preconceito ao longo do desenvolvimento, o que suporta a ideia de que as crianças com a idade começam a controlar as suas respostas preconceituosas (Rutland et al., 2007) e a avaliar diferentes grupos sociais de acordo com as normas de equidade (Monteiro et al., 2009).

\section{Contacto Interétnico}

O contacto interpessoal tem um papel fundamental no preconceito étnico e deve, portanto, ser tido em conta aquando do seu estudo. A Hipótese do Contacto de Allport defende que o aumento da familiaridade com um grupo pode levar a uma maior aquisição de opiniões corretas sobre o mesmo (Alfieri \& Marta, 2015).

A meta-análise de Pettigrew e Tropp (2006), que inclui 500 estudos com amostras étnicas e não étnicas de diferentes faixas etárias, incluindo crianças e adolescentes, revelou uma relação negativa entre contacto e preconceito. Outros estudos demonstram igualmente a existência de uma associação negativa entre ambos (Falanga et al., 2014).

É importante ter em consideração que a grande maioria dos estudos se foca nas atitudes de membros de grupos maioritários (Falanga et al., 2014), tendo como alvo os grupos minoritários. A forma como o contacto produz efeito no preconceito pode não resultar da mesma forma em grupos minoritários e maioritários (Brown, 2010).

O preconceito e discriminação raciais têm inúmeras consequências para quem é alvo dos mesmos, nomeadamente: efeitos negativos e mais problemas tanto na saúde física como mental (Alamilla et al., 2017); depressão e níveis mais baixos de satisfação com a vida; ter menor acesso a cuidados de saúde ou cuidados de pior qualidade; falta de acesso a determinados empregos (Stangor, 2016); rejeição da própria imagem por interiorização dos estereótipos negativos (Máximo et al., 2012). Importa ainda destacar o forte impacto negativo nas crianças e jovens ao nível do rendimento escolar, autoestima, autoeficácia, desenvolvimento socioemocional, relações interpessoais e exclusão social (Berger et al., 2016).

0 estudo do preconceito e discriminação raciais permite uma melhor compreensão de como reduzir, eliminar ou reverter os processos que iniciam ou mantêm essas manifestações de conflitos intergrupais (Gaertner et al., 2016). Desta forma, é fundamental o seu estudo, nomeadamente na escola, pela sua contribuição no desenvolvimento de programas eficazes no âmbito da educação intercultural (Sarafidou et al., 2014).

Embora os grupos raciais possam ser considerados como algo contínuo, a sua concetualização em categorias separadas permite um conhecimento mais profundo sobre como os indivíduos categorizam as pessoas birraciais (Young et al., 2017). Vários estudos consideram as pessoas birraciais como pertencentes a um grupo racial específico que é aceite como distinto dos restantes; crianças mulatas reconhecem e afirmam a sua pertença à categoria mulata (Monteiro, 2002).

Tendo em conta o exposto anteriormente, o presente estudo é relevante já que: a) utiliza 3 grupos raciais (crianças brancas, mulatas e negras) nos grupos em estudo e grupos alvo de preconceito, existindo 
assim dois grupos minoritários; tal possibilita minimizar possíveis erros na interpretação que podem existir no estudo de um único endogrupo face a um único exogrupo (Clark et al., 2017); b) são as próprias crianças a definirem a sua pertença ao grupo racial através do processo de autocategorização; c) estuda a identidade étnica na perspetiva de verificar se existem diferenças nas manifestações de preconceito e não como recurso para lidar com as consequências em quem é alvo de preconceito. Em termos de implicações práticas, pretendemos que os conhecimentos provenientes do presente estudo permitam definir práticas educativas mais eficazes.

\section{OBJETIVOS DO ESTUDO}

Pretende-se estudar se a identificação étnica de crianças que se autocategorizam como brancas (B), mulatas (M) e negras (N) leva a diferenças na expressão do preconceito racial face a pessoas Mulatas, Negras e Brancas. Tem-se ainda em consideração as variáveis Contacto Interétnico e Distância Social.

São objetivos específicos deste estudo: a) analisar se existem diferenças no preconceito racial em função da identificação étnica (autocategorização e avaliação emocional da pertença); b) analisar se existem diferenças na distância social em função da identificação étnica (autocategorização e avaliação emocional da pertença); c) analisar se existem diferenças no preconceito racial em função do sexo; d) analisar se o preconceito racial se correlaciona com a distância social; e) analisar se o contacto interétnico se correlaciona com o preconceito racial e a distância social.

\section{MÉTODO}

\section{Participantes}

A amostra foi composta por alunos/as do 2.ํ ciclo do Ensino Básico de escolas de Setúbal e Amadora. Recorreu-se a uma amostragem não-probabilística de conveniência (Marôco, 2014), tendo sido recolhidos 340 questionários. Destes, 75 foram excluídos por estarem incompletos, terem sido respondidos ao acaso e/ou pela existência de respostas idênticas ("copiadas") face aos três grupos raciais; excluíram-se ainda 7 questionários de crianças que se autocategorizaram como negras (que, pelo seu número reduzido, não possibilitavam a comparação com os outros grupos). Assim, a amostra final é composta por 258 participantes $(N=258)$, de 4 escolas públicas, de Setúbal e da Damaia, Amadora. Do total de alunos/as, 157 (60.9\%) frequentam o 5.. ano e 101 (39.1\%) frequentam o 6. ano de escolaridade. A idade dos participantes varia entre os 9 e os 14 anos $(M=11.19$; $M d n=11)$, sendo que 141 (54.7\%) são do sexo masculino e 117 (45.3\%) do sexo feminino. Desses 258 participantes, 187 (72.5\%) autocategorizam-se como brancos (Grupo B) e 71 (27.5\%) como mulatos (Grupo M).

\section{Instrumento}

Para a recolha de dados foi construído um questionário, o Questionário de Atitudes e Relações Intergrupais (QARI), com o intuito de avaliar a Identificação étnica/grupal (em termos de Autocategorização e Avaliação Emocional da Pertença), o Contacto Interétnico, a Distância Social e o Preconceito Racial. A Distância Social e Preconceito Racial são avaliados face a 3 grupos raciais - pessoas negras, mulatas e brancas. Foi também construído um questionário sociodemográfico de modo a possibilitar a caracterização da amostra, em termos de idade e sexo. Os dados relativos à escola e ano de escolaridade foram recolhidos presencialmente.

O QARI contém uma breve introdução onde é referido o seu objetivo e o caráter anónimo e confidencial do seu preenchimento. A Identificação Étnica é composta por 3 itens, o Contacto Interétnico por 6 itens, a Distância Social por 24 itens ( 8 itens face a pessoas brancas, 8 face negras e 8 face a mulatas) e o Preconceito Racial por 27 itens no total ( 9 para cada um dos 3 grupos em estudo). A distância social e o preconceito racial são avaliados numa escala de quatro pontos. Optou-se por esta escala de resposta de forma a minimizar o erro de tendência central, já que o ponto central pode gerar ambivalência e indiferença, divergindo a resposta da verdadeira opinião do/a respondente (Collings, 2006). Também foi tida em linha de conta a idade dos/as participantes, visto que a complexidade aumenta com o número de pontos da escala (Dalmoro \& Vieira, 2013).

O preconceito no QARI, operacionalizado através das escalas de Distância Social e de Preconceito Racial, é avaliado, portanto, em múltiplos grupos alvo (N, M e B) e grupos em estudo (B e M), com o intuito, para além da comparação entre grupos, colmatar também possíveis falhas na interpretação dos resultados (Clark et al., 2017).

Identificação Étnica. A identificação étnica incorpora a autocategorização e avaliação emocional da pertença enquanto componente afetiva da pertença e foi avaliada pelos/as participantes através de três questões, tendo por base o questionário desenvolvido por França e Monteiro (2002), bem como itens 
utilizados nos estudos de Máximo e colegas (2012) e de Mouro e colaboradores (2002). A primeira questão é de autocategorização ("Tendo em conta as crianças nas imagens, com qual te pareces mais?") e foi obtida através do auxílio de imagens estímulo. Como estímulo foram utilizados emojis com a face de crianças de três cores de pele, de rapazes e raparigas, de acordo com o sexo do/a participante. Optou-se pela utilização de emojis com o intuito de alterar apenas a cor de pele e não as outras características faciais.

As duas questões seguintes referem-se à componente afetiva: "Gostas de estar nesse grupo?", com uma escala de resposta de 4 pontos (de "Não Gosto Nada" a "Gosto Muito"), e "Onde gostarias de estar?", com três possibilidades de resposta - A, B e C. 0 grupo $\mathrm{A}$ refere-se à cor de pele branca, o Grupo $\mathrm{B}$ à cor de pele mulata e o Grupo $\mathrm{C}$ à cor de pele negra (corresponde às letras existentes no material de estímulo).

Contacto Interétnico. Nesta parte do questionário pretende-se explorar a "quantidade" de contacto existente, tendo como base as medidas utlizadas por Alfieri e Marta (2015) e Tredoux e Finchilescu (2010). A questão "Conheces pessoas de vários grupos étnicos (pessoas de cores diferentes)?" é composta por 6 itens de resposta que se refere a diferentes situações de contacto (vizinhos, colegas da escola, colegas da turma, amigos, pessoas com quem mora e pessoas da família) e pretende verificar se existe contacto com os 3 grupos raciais. Desta forma, para cada item é colocada uma cruz no(s) grupo(s) com o(s) qual(is) tenha contacto; por exemplo, no item dos/as amigos/as, se tiver amigos dos 3 grupos étnicos são colocadas 3 cruzes que correspondem à coluna das pessoas mulatas, à das pessoas negras e à coluna das pessoas brancas.

Distância Social. A distância social "mede uma manifestação importante do preconceito e da discriminação social, como uma escala tradutora do grau de intimidade ou tolerância que estamos dispostos a aceitar em relação a membros de um grupo social" (Marques et al., 2013, p. 445). Como a distância social pode ser considerada uma forma de preconceito (Tredoux \& Finchilescu, 2010), trata-se no presente estudo de uma forma de operacionalizar o preconceito.

A construção das questões relativas a esta componente teve por base a Escala de Distância Social de Bogardus e outros questionários já existentes sobre esta temática (Alexandre et al., 2007; França \& Monteiro, 2002; Tredoux \& Finchilescu, 2010).

No QARI, a Distância Social é avaliada através de 8 itens e mede o grau de intimidade que é aceite face a determinado grupo étnico ( $\mathrm{M}, \mathrm{N}$ e B). $\mathrm{O}$ /a participante indica o quanto gostaria que cada uma das situações descritas nos itens acontecesse (e.g. que fosse da tua equipa desportiva), com uma escala de resposta de 4 pontos (de "Não Gostava Nada” a “Gostava Muito"). Valores elevados indicam maior distância social, ou seja, menor disponibilidade para contacto social com membros de determinado grupo étnico (Berger et al., 2016).

Preconceito Racial. A maior parte dos estudos com crianças foca-se na preferência racial; no entanto Bennet e colaboradores (2004) consideram que esta é insuficiente para averiguar a existência de preconceito étnico, visto que a preferência não significa necessariamente a desvalorização do exogrupo. Por esse motivo, considerou-se necessária a construção de uma escala, que se baseou no questionário de preconceito subtil e flagrante de Sarafidou e colegas (2014) e nas questões mais subtis de preconceito, nomeadamente o facto de que o preconceito atualmente se pode traduzir mais pela negação de emoções e traços positivos relativamente ao grupo alvo/exogrupo e não tanto pela atribuição de traços ou emoções negativas (Vala et al., 2015).

No QARI, o Preconceito Racial é composto por 9 itens, em que os participantes indicam a sua opinião numa possibilidade de 4 respostas (de "Discordo Muito" a "Concordo Muito"). Valores mais elevados na escala indicam mais preconceito racial.

Após a construção inicial do questionário foi realizado um estudo piloto prévio à recolha dos dados de modo a verificar a sua adequabilidade e identificar possíveis problemas que pudessem afetar a qualidade e validade dos resultados.

\section{Procedimento}

Após obtenção de autorização por parte do Ministério da Educação, foram realizados contactos com Direções de Agrupamentos/Escolas de Setúbal, Amora/Seixal e Amadora para obtenção da autorização relativa à aplicação dos questionários. As zonas das escolas foram escolhidas por terem à partida uma maior diversidade racial, o que correspondia aos objetivos de investigação.

Nas 4 escolas que responderam de forma positiva, foram entregues 559 consentimentos informados aos/às Encarregados/as de Educação, onde constavam os objetivos da investigação e a garantia de anonimato e confidencialidade dos dados obtidos. Na totalidade foram recolhidos 340 questionários. 
A recolha dos dados ocorreu durante o 2. e o 3. período do ano letivo de 2016/2017 e foi efetuada de forma presencial em contexto turma. 0 QARI foi impresso em forma de livro A5, tendo sido feito um contrabalanceamento dos grupos raciais no questionário, ou seja, foram criadas 6 versões distintas tendo em conta as combinações possíveis em termos de sequência $\mathrm{B}, \mathrm{M}$ e $\mathrm{N}$ e foram baralhados antes de serem distribuídos.

Os dados obtidos foram analisados através do software de análise estatística IBM SPSS Statistics tendo em conta a natureza métrica das variáveis.

\section{RESULTADOS}

\section{Estudos Psicométricos}

\section{Distância Social}

Análise Fatorial Exploratória. Previamente à realização da Análise Fatorial Exploratória (AFE), verificouse a sua adequabilidade à matriz dos dados com um valor considerado bom $(K M O=0.90)$, e do Teste de Esfericidade de Bartlett que apresenta um $p$-value $<0.001$. Procedeu-se à AFE com extração dos fatores pelo método dos componentes principais, seguida de rotação ortogonal (varimax). Seguindo a regra do eigenvalue superior a 1, da variância extraída de cada fator, do valor do teste do KMO e pelo facto da eliminação de itens não contribuir para uma melhor interpretação da estrutura fatorial, optou-se pela AFE forçada a 3 fatores, explicativos de $58 \%$ da variância total.

Cada um dos fatores agrupou os itens referentes a cada um dos grupos raciais/étnicos. A primeira dimensão, relativa à "Distância Social face a pessoas Negras", apresenta pesos fatoriais elevados e explica $35.2 \%$ da variância total. A segunda dimensão, "Distância Social face a pessoas Brancas", com pesos fatoriais elevados explica $15.1 \%$ da variância total. A terceira dimensão relativa à "Distância Social face a pessoas Mulatas" apresenta pesos fatoriais elevados e explica 7.8\% da variância total. Na Tabela 1 resumem-se os pesos fatoriais de cada item em cada um dos três fatores, os seus eigenvalues, a comunalidade de cada item e a percentagem de variância explicada por cada fator. 
Tabela 1. Pesos fatoriais de cada item nos fatores, comunalidades, eigenvalues e percentagem de variância explicada na escala de Distância Social

\begin{tabular}{|c|c|c|c|c|}
\hline \multirow{2}{*}{ Item } & \multicolumn{3}{|c|}{ Fator } & \multirow{2}{*}{ Comunalidade } \\
\hline & 1 & 2 & 3 & \\
\hline N - De convidar para a tua festa de aniversário & .814 & .087 & .131 & .687 \\
\hline $\mathrm{N}$ - Que fosse do teu grupo de amigos/as & .785 & .029 & .256 & .682 \\
\hline $\mathrm{N}$ - Que fosse da tua turma & .772 & .177 & .223 & .677 \\
\hline N - Que fosse teu/tua melhor amigo/a & .767 & .041 & .273 & .664 \\
\hline $\mathrm{N}$ - De fazer um trabalho da escola & .761 & .110 & .117 & .605 \\
\hline $\mathrm{N}$ - De passar os tempos livres & .734 & .070 & .270 & .616 \\
\hline $\mathrm{N}$ - Que fosse da tua equipa desportiva & .679 & .094 & .240 & .528 \\
\hline $\mathrm{N}$ - Que fosse teu/tua irmão/irmã adotivo/a & .678 & -.039 & .299 & .551 \\
\hline B - Que fosse do teu grupo de amigos/as & .121 & .770 & .088 & .615 \\
\hline B - De passar os tempos livres & -.019 & .747 & .123 & .574 \\
\hline B - Que fosse da tua equipa desportiva & .024 & .734 & .194 & .577 \\
\hline B - Que fosse teu/tua melhor amigo/a & .097 & .732 & .093 & .554 \\
\hline B - De convidar para a tua festa de aniversário & .084 & .730 & .149 & .562 \\
\hline B - De fazer um trabalho da escola & .150 & .723 & .077 & .551 \\
\hline B - Que fosse da tua turma & .141 & .720 & .131 & .555 \\
\hline B - Que fosse teu/tua irmão/irmã adotivo/a & -.060 & .621 & .184 & .424 \\
\hline M - Que fosse teu/tua melhor amigo/a & .204 & .151 & .742 & .615 \\
\hline M - De convidar para a tua festa de aniversário & .210 & .167 & .707 & .572 \\
\hline M - Que fosse do teu grupo de amigos/as & .344 & .121 & .707 & .632 \\
\hline M - Que fosse da tua equipa desportiva & .132 & .140 & .703 & .531 \\
\hline M - De passar os tempos livres & .228 & .207 & 699 & .584 \\
\hline M - De fazer um trabalho da escola & .218 & .190 & .684 & .552 \\
\hline M - Que fosse teu/tua irmão/irmã adotivo/a & .200 & .053 & .641 & .454 \\
\hline M - Que fosse da tua turma & .340 & .224 & .627 & .559 \\
\hline Eigenvalue & 8.44 & 3.61 & 1.87 & - \\
\hline \%Variância explicada & 35.15 & 15.06 & 7.80 & - \\
\hline
\end{tabular}

Nota. A negrito são apresentados os itens com pesos fatoriais superiores a 0.40 em valor absoluto.

Validade e Fiabilidade de Constructo. Como se pode constatar na Tabela 1, todos os itens apresentam pesos fatoriais nos respetivos fatores superiores a 0.50 , revelando, portanto que os três fatores apresentam validade fatorial.

Na Tabela 2 são apresentados os valores da validade convergente e discriminante e da consistência interna da análise fatorial exploratória. Quanto à validade convergente dos fatores, a variância média extraída revelou-se adequada, apresentando todos os fatores valores superiores a 0.5 ( 0.77 para o fator 1 e 0.76 para os dois restantes). Também a validade discriminante de todos os fatores foi demonstrada, visto que as suas correlações ao quadrado são consideravelmente inferiores aos seus valores de VME, de forma que os fatores são distintos entre si. No que respeita aos níveis de consistência interna obtidos pela fiabilidade compósita, estes revelaram-se bastante bons, com todos os valores iguais ou superiores a 0.90 .

Tabela 2. Validade Convergente, Fiabilidade Compósita e Validade Discriminante da escala de Distância Social

\begin{tabular}{lccccc}
\hline & VME & FC & \multicolumn{3}{c}{$\boldsymbol{r}^{\mathbf{2}}$} \\
\cline { 4 - 6 } & & .91 & $\mathbf{1}$ & $\mathbf{2}$ & $\mathbf{3}$ \\
\hline 1. DS Negros & .77 & .90 & - & - & - \\
2. DS Brancos & .76 & .90 & .31 & - & - \\
3. DS Mulatos & .76 & .90 & .07 & - \\
\hline
\end{tabular}




\section{Preconceito Racial}

Análise Fatorial Exploratória. Após verificação dos pré-requisitos necessários (KMO = .81; teste de esfericidade de Bartlett <.001), procedeu-se à análise fatorial exploratória pelo método dos componentes principais, seguida de rotação ortogonal (varimax). Foi obtida uma estrutura fatorial constituída por 7 fatores explicativos de $63.6 \%$ da variância total.

$\mathrm{Na}$ Tabela 3 resumem-se os pesos fatoriais de cada item em cada um dos 7 fatores, os seus eigenvalues, a comunalidade de cada item e a percentagem de variância explicada por cada fator.

0 primeiro fator apresenta pesos fatoriais elevados e explica $22.8 \%$ da variância total, sendo composto por 6 itens relativos a "Qualidades Pessoais de crianças Negras, Mulatas e Brancas". O segundo fator constituído por 6 itens, explica 13.8\% da variância total e agrupa os itens relacionados com os "Interesses e Participação na sala de aula de crianças Negras, Mulatas e Brancas". 0 terceiro fator composto por 3 itens, explicativo de 7.3\% da variância total, agrega os itens relacionados com as "Dificuldades Escolares de crianças Negras, Mulatas e Brancas". O fator quatro, explicativo de 5.9\% da variância total, agrupa 4 itens que se referem ao evitamento e à criação de mais problemas em sala de aula por parte de crianças negras e mulatas, pelo que foi designado de "Preconceito face a crianças Mulatas e Negras". 0 fator 5 composto pelos itens relativos a "Mentalidades Diferentes das crianças Negras, Mulatas e Brancas" explica 5\% da variância total. 0 fator 6 explicativo de $4.6 \%$ da variância total é composto por 3 itens (crianças tendem a formar grupo entre si), designando-se de "Relações Intergrupais de crianças Negras, Mulatas e Brancas". Por último, o fator 7 "Preconceito face a crianças Brancas" é constituído por dois itens e explica $4.3 \%$ da variância total. Apesar deste último fator ser pobre em termos de número de itens, tem pesos fatoriais elevados, um valor de percentagem de variância explicada perto da do fator 6 e consistência interna adequada (Tabela ). Por se tratar da construção de uma escala, consideramos que seria prematuro eliminar o fator ou retirar itens da escala. Para além disso, o número de fatores da AFE (7) é adequado tendo em conta o número de itens total (Tabachnick \& Fidell, 2013). 
Tabela 3. Pesos fatoriais de cada item nos fatores, comunalidades, eigenvalues e percentagem de variância explicada na escala de Preconceito Racial

\begin{tabular}{|c|c|c|c|c|c|c|c|c|}
\hline \multirow{2}{*}{ Item } & \multicolumn{7}{|c|}{ Fator } & \multirow{2}{*}{ Com. } \\
\hline & 1 & 2 & 3 & 4 & 5 & 6 & 7 & \\
\hline 1M. ...mulatas são de confiança e boas amigas. & .774 & .019 & .091 & -.075 & -.130 & .052 & .021 & .633 \\
\hline 2B. ...crianças brancas têm boas qualidades. & .755 & .150 & -.042 & .221 & -.008 & -.041 & -.121 & .659 \\
\hline 2M. ...crianças mulatas têm boas qualidades. & .753 & .200 & -.178 & .022 & .113 & -.029 & .030 & .654 \\
\hline 1N. ...negras são de confiança e boas amigas. & .672 & .177 & .076 & -.385 & -.130 & -.010 & .061 & .658 \\
\hline 1B. ...brancas são de confiança e boas amigas. & .654 & .008 & .221 & .216 & -.110 & .105 & -.268 & .618 \\
\hline 2N. ...crianças negras têm boas qualidades. & .651 & .278 & -.138 & -.289 & .069 & .018 & .058 & .613 \\
\hline $\begin{array}{l}5 \mathrm{~N} \text {. ...os mesmos interesses que os seus } \\
\text { colegas. }\end{array}$ & .162 & .721 & .040 & -.222 & -.247 & .078 & .161 & .689 \\
\hline $\begin{array}{l}5 \mathrm{M} \text {....os mesmos interesses que os seus } \\
\text { colegas. }\end{array}$ & .137 & .716 & -.033 & .045 & -.123 & .001 & .069 & .555 \\
\hline 4M. ...participam na aula da mesma maneira... & .075 & .693 & -.164 & -.157 & .019 & .017 & -.134 & .556 \\
\hline 5B. ... mesmos interesses que os seus colegas. & .225 & .639 & .006 & .363 & -.075 & .070 & -.122 & .617 \\
\hline 4N. ... participam na aula da mesma maneira... & .156 & .597 & -.141 & -.401 & -.189 & .014 & .061 & .601 \\
\hline 4B. ...participam na aula da mesma maneira... & .080 & .585 & -.117 & -.002 & .038 & -.057 & -.438 & .558 \\
\hline 8M. ...dificuldades com os trabalhos da escola. & .030 & -.193 & .809 & .138 & .202 & .051 & .108 & .767 \\
\hline 8N. ...dificuldades com os trabalhos da escola. & .000 & -.092 & .761 & .143 & .255 & .129 & .036 & .690 \\
\hline 8B. ...dificuldades com os trabalhos da escola. & -.018 & .001 & .707 & .144 & .094 & .115 & .203 & .584 \\
\hline 3N. É melhor evitar crianças negras... & -.065 & -.033 & .167 & .748 & .124 & .050 & .166 & .638 \\
\hline 3M.É melhor evitar crianças mulatas... & .019 & -.096 & .098 & .610 & .115 & .097 & .444 & .611 \\
\hline 6N. ...criam mais problemas na aula do que... & -.065 & -.045 & .431 & .540 & .170 & .127 & .049 & .531 \\
\hline 6M. ...criam mais problemas na aula do que... & .101 & -.125 & .309 & .465 & .262 & .055 & .227 & .461 \\
\hline 9N. ...negras têm uma mentalidade diferente. & -.125 & -.132 & .186 & .202 & .797 & .123 & .059 & .762 \\
\hline 9M. ...mulatas têm uma mentalidade diferente. & -.006 & -.200 & .236 & .220 & .772 & .051 & .119 & .756 \\
\hline 9B. ...brancas têm uma mentalidade diferente. & -.019 & -.077 & .201 & .017 & .759 & .144 & .229 & .696 \\
\hline $\begin{array}{l}\text { 7M. ...mulatas tendem a formar grupos entre } \\
\text { si. }\end{array}$ & .060 & .016 & .121 & .111 & .114 & .840 & .082 & .757 \\
\hline 7N. ...negras tendem a formar grupos entre si. & .077 & .085 & .092 & -.052 & .152 & .784 & .067 & .666 \\
\hline 7B. ...brancas tendem a formar grupos entre si. & -.068 & -.013 & .065 & .109 & -.003 & .767 & .016 & .610 \\
\hline 3B. É melhor evitar crianças brancas... & -.039 & .033 & .105 & .179 & .136 & .080 & .787 & .690 \\
\hline 6B. ...criam mais problemas na aula do que... & -.074 & -.073 & .227 & .198 & .238 & .065 & .608 & .531 \\
\hline Eigenvalue & 6.15 & 3.73 & 1.96 & 1.58 & 1.36 & 1.23 & 1.60 & - \\
\hline \% Variância explicada & 22.76 & 13.80 & 7.26 & 5.85 & 5.02 & 4.56 & 4.30 & - \\
\hline
\end{tabular}

Nota. A negrito são apresentados os itens com pesos fatoriais superiores a 0.40 em valor absoluto. (Com.=Comunalidade).

Validade e Fiabilidade de Constructo. Quanto à validade fatorial, é possível verificar na Tabela 3 que, à exceção do item 6 face a M que tem um valor ligeiramente abaixo do valor considerado apropriado, todos os pesos fatoriais apresentam valores superiores a 0.50 , considerando-se que os 7 fatores apresentam validade fatorial. Na Tabela 4 verifica-se que os fatores apresentam valores de VME adequados (superiores a 0.5) que são indicativos de validade convergente. A validade discriminante dos fatores também foi demonstrada, visto que as VME dos fatores foram superiores ao quadrado das correlações entre os mesmos. Quanto à consistência interna dos itens reflexivos dos fatores, a FC revelou-se elevada com todos os valores situados acima de 0.7 (indicador de valor adequado). 
Tabela 4. Validade Convergente, Fiabilidade Compósita e Validade Discriminante da escala de Preconceito Racial

\begin{tabular}{lccccccccc}
\hline & & VME & FC & \multicolumn{7}{c}{$\boldsymbol{r}^{\mathbf{2}}$} \\
\cline { 5 - 10 } & & & $\mathbf{1}$ & $\mathbf{2}$ & $\mathbf{3}$ & $\mathbf{4}$ & $\mathbf{5}$ & $\mathbf{6}$ & $\mathbf{7}$ \\
\hline Fator 1 & .90 & .95 & - & - & - & - & - & - & - \\
Fator 2 & .77 & .87 & .53 & - & - & - & - & - & - \\
Fator 3 & .83 & .84 & .32 & .33 & - & - & - & - & - \\
Fator 4 & .73 & .76 & .03 & .20 & .00 & - & - & - & - \\
Fator 5 & .86 & .87 & .08 & .02 & .03 & .23 & - & - & - \\
Fator 6 & .83 & .86 & .00 & .03 & .02 & .01 & .41 & - & - \\
Fator 7 & .78 & .71 & .03 & .04 & .64 & .19 & .00 & .05 & - \\
\hline
\end{tabular}

\section{Estudos Inferenciais}

\section{Identificação Étnica}

Preconceito Racial. Através do Teste $t$-Student verificou-se que não existem diferenças estatisticamente significativas no que se refere tanto ao grupo de autocategorização (Grupo B e M), como à avaliação emocional da pertença, no que se refere ao preconceito face aos 3 grupos étnicos.

Distância Social. De acordo com o Teste t-Student (Tabela 5), existem diferenças estatisticamente significativas entre os dois grupos de autocategorização ao nível da Distância Social face a pessoas Mulatas, $t(256)=3.71, p<.001$, Negras, $t(256)=2.74, p=.007$, e Brancas, $t(255)=2.97, p=.003$. Neste sentido, os resultados parecem demonstrar que o grupo B apresenta maiores níveis de Distância Social face a pessoas mulatas e negras do que o Grupo M, enquanto este último apresenta maior Distância Social face a pessoas brancas do que o Grupo B.

Tabela 5. Teste t-Student: Distância Social face aos 3 grupos raciais em função do grupo de autocategorização

\begin{tabular}{|c|c|c|c|c|}
\hline \multirow[b]{2}{*}{ Distância Social } & \multicolumn{2}{|c|}{ Grupo Étnico } & \multirow[b]{2}{*}{$t$} & \multirow[b]{2}{*}{$p$} \\
\hline & $\begin{array}{c}\text { Grupo B } \\
M \text { (DP) }\end{array}$ & $\begin{array}{c}\text { Grupo M } \\
M \text { (DP) }\end{array}$ & & \\
\hline Distância Social M & $13.31(3.67)$ & $11.48(3.20)$ & 3.71 & $<.001$ \\
\hline Distância Social N & $14.66(4.44)$ & $12.97(4.399$ & 2.74 & .007 \\
\hline Distância Social B & $11.57(3.23)$ & $12.94(3.46)$ & 2.97 & .003 \\
\hline
\end{tabular}

Relativamente à avaliação emocional da pertença ${ }^{3}$, e como se pode constatar na Tabela 6, verifica-se que no Grupo B (crianças brancas) existem diferenças estatisticamente significativas ao nível da distância Social face a pessoas brancas, em função da AEP (gostar), $t(181)=3.21, p=.002$. Quanto à AEP relativa ao grupo onde gostaria de estar (igual/diferente do de autocategorização), existem diferenças estatisticamente significativas ao nível da distância social face a pessoas mulatas, $t(184)=2.23, p=.027$, e da distância social face a pessoas negras, $t(184)=2.93, p=.004)$. Neste sentido, os resultados parecem demonstrar que, no Grupo B, quem "gosta muito" do grupo de autocategorização apresenta menores níveis de distância social face a pessoas brancas do que quem "gosta". Por outro lado, quem gostaria de se manter no seu grupo de autocategorização parece demonstrar maior distância social face a pessoas negras e maior distância social face a pessoas mulatas, em comparação com gostaria de estar num grupo diferente.

\footnotetext{
${ }^{3}$ A identificação étnica é medida através da autocategorização e da avaliação emocional da pertença. Gostar muito de estar no grupo de autocategorização e querer manter-se no mesmo indicam níveis mais elevados de avaliação emocional da pertença. Tendo em conta o número reduzido de respostas "não gosto", os testes de comparação de médias foram efetuados apenas relativamente a dois tipos de resposta - "Gosto" e "Gosto Muito".
} 
Tabela 6. Teste t-Student: Distância Social em função da AEP no Grupo B (crianças brancas)

\begin{tabular}{|c|c|c|c|c|}
\hline & \multicolumn{2}{|c|}{ Gostas de estar nesse Grupo? } & \multirow[b]{2}{*}{$t$} & \multirow[b]{2}{*}{$p$} \\
\hline & $\begin{array}{c}\text { Gosto } \\
M \text { (DP) }\end{array}$ & $\begin{array}{c}\text { Gosto Muito } \\
M \text { (DP) } \\
\end{array}$ & & \\
\hline Distância Social M & $13.30(3.44)$ & $13.26(3.84)$ & .06 & .949 \\
\hline Distância Social N & $14.02(4.01)$ & $15.15(4.71)$ & 1.73 & .086 \\
\hline \multirow[t]{3}{*}{ Distância Social B } & $12.37(3.42)$ & $10.87(2.92)$ & 3.21 & .002 \\
\hline & \multicolumn{2}{|c|}{ Grupo onde Gostava de Estar } & & \\
\hline & $\begin{array}{c}\text { Igual } \\
M \text { (DP) }\end{array}$ & $\begin{array}{c}\text { Diferente } \\
M \text { (DP) }\end{array}$ & & \\
\hline Distância Social M & $13.64(3.52)$ & $12.26(3.96)$ & 2.23 & .027 \\
\hline Distância Social N & $15.19(4.20)$ & $13.02(4.81)$ & 2.93 & .004 \\
\hline Distância Social B & $11.58(3.19)$ & $11.46(3.35)$ & .22 & .824 \\
\hline
\end{tabular}

No grupo M (crianças mulatas) e conforme a Tabela 7, pode-se verificar que existem diferenças estatisticamente significativas entre a AEP (gostar) e o nível da distância social face a pessoas mulatas, $t(67)=2.86, p=.006$, e negras, $t(67)=4.29, p<.001)$. Por outro lado, existem diferenças estatisticamente significativas entre a AEP (enquanto grupo onde gostaria de estar) ao nível da distância social face a pessoas negras, $t(68)=3.49, p=.001$ ). Desta forma, parece que, no grupo $\mathrm{M}$, os/as participantes que "gostam muito" do seu grupo de autocategorização apresentam menores níveis de distância social face a pessoas mulatas e pessoas negras. Por outro lado, os/as que gostariam de se manter no grupo de autocategorização parecem demonstrar menores níveis de distância social face a pessoas negras.

Tabela 7. Teste t-Student: Distância Social em função da AEP no Grupo M (crianças mulatas)

\begin{tabular}{|c|c|c|c|c|}
\hline & \multicolumn{2}{|c|}{ Gostas de estar nesse Grupo? } & \multirow[b]{2}{*}{$\boldsymbol{t}$} & \multirow[b]{2}{*}{$p$} \\
\hline & $\begin{array}{c}\text { Gosto } \\
M \text { (DP) } \\
\end{array}$ & $\begin{array}{c}\text { Gosto Muito } \\
M(\mathrm{DP}) \\
\end{array}$ & & \\
\hline Distância Social M & $12.76(3.17)$ & $10.63(2.98)$ & 2.86 & .006 \\
\hline Distância Social N & $14.69(3.85)$ & $11.10(3.10)$ & 4.29 & $<.001$ \\
\hline \multirow[t]{3}{*}{ Distância Social B } & $13.52(3.49)$ & $12.56(3.45)$ & 1.12 & .269 \\
\hline & \multicolumn{2}{|c|}{ Grupo onde Gostava de Estar } & & \\
\hline & $\begin{array}{c}\text { Igual } \\
M \text { (DP) }\end{array}$ & $\begin{array}{c}\text { Diferente } \\
M \text { (DP) }\end{array}$ & & \\
\hline Distância Social M & $11.61(3.18)$ & $10.67(3.61)$ & .81 & .418 \\
\hline Distância Social N & $12.33(3.88)$ & $17.44(5.50)$ & 3.49 & .001 \\
\hline Distância Social B & $12.70(3.51)$ & $14.22(2.82)$ & 1.23 & .222 \\
\hline
\end{tabular}

\section{Preconceito Racial}

Sexo. Existem diferenças estatisticamente significativas entre as participantes do sexo feminino e os participantes do sexo masculino ao nível do preconceito face a pessoas mulatas, $t(256)=3.96, p<.001$ ), negras, $t(256)=3.85, p<.001$, e brancas, $t(256)=3.69, p<.001$. Os resultados obtidos parecem então demonstrar que, na amostra total, os rapazes manifestam atitudes mais preconceituosas face aos 3 grupos raciais. 0 mesmo se verificou nos dois grupos de autocategorização: no grupo B face a pessoas mulatas, $t(185)=3.28, p=.001$, negras, $t(185)=2.99, p=.003$, e brancas, $t(185)=2.12, p=.035$, e no Grupo M face a pessoas mulatas, $t(69)=2.19, p=.021$, negras, $t(69)=2.46, p=.016$, e brancas, $t(69)=3.76, p<.001$.

Distância Social. A Tabela 8 mostra as correlações existentes entre a distância social e o preconceito racial face aos 3 grupos raciais, em função do grupo de autocategorização. Tal como se pode verificar, no Grupo B (crianças brancas) a distância social face a pessoas mulatas correlaciona-se de forma positiva moderada com preconceito face a pessoas mulatas, $r=.38, p<.01$, e negras, $r=.35, p<.01$, e de forma positiva fraca com o preconceito face a pessoas brancas, $r=.23, p<.01$. No mesmo sentido, a distância social face a pessoas negras correlaciona-se de forma moderada e positiva com o preconceito racial face a pessoas mulatas, $r$ $=.33, p<.01$, e negras, $r=.49, p<.01$, e de forma fraca e positiva com o preconceito racial face a pessoas brancas, $r=.19, p<.01$. A distância social face a pessoas brancas correlaciona-se de forma fraca e positiva com o preconceito racial face a pessoas brancas, $r=.16, p<.05$. No Grupo M (crianças mulatas) pode-se 
verificar a existência de apenas uma correlação positiva moderada entre a distância social face a pessoas brancas e o preconceito face a pessoas brancas, $r=.25, p<.05$.

A distância social de forma global relaciona-se de forma positiva com o preconceito racial: no grupo das crianças brancas as correlações moderadas verificam-se entre a distância social face a pessoas mulatas e negras e ao preconceito face às mesmas; no sentido inverso, nas crianças mulatas o resultado significativo é referente às pessoas brancas.

Tabela 8. Correlações entre o preconceito e a distância social face aos 3 grupos raciais em função do grupo de autocategorização

\begin{tabular}{lcccccc}
\hline & $\mathbf{1}$ & $\mathbf{2}$ & $\mathbf{3}$ & $\mathbf{4}$ & $\mathbf{5}$ & $\mathbf{6}$ \\
\hline 1. Preconceito M & - & $.79^{* *}$ & $.62^{* *}$ & $.38^{* *}$ & $.33^{* *}$ & .09 \\
2. Preconceito N & $.70^{* *}$ & - & $.55^{* *}$ & $.35^{* *}$ & $.49^{* *}$ & .06 \\
3. Preconceito B & $.63^{* *}$ & $.61^{* *}$ & - & $.23^{* *}$ & $.19^{* *}$ & $.16^{*}$ \\
4. Distância Social M & -.03 & .03 & .06 & - & $.63^{* *}$ & $.45^{* *}$ \\
5. Distância Social N & .08 & .21 & .20 & $.36^{* *}$ & - & $.26^{* *}$ \\
6. Distância Social B & .09 & .12 & $.25^{*}$ & $.47^{* *}$ & $.24^{*}$ & - \\
\hline
\end{tabular}

Nota. Correlações para o Grupo B (n=187) são apresentadas por cima da diagonal e as correlações para o Grupo M $(\mathrm{n}=71)$ são apresentados por baixo da diagonal. Nível de significância: ${ }^{* *} p<.01 ;{ }^{*} p<.05$.

Contacto Interétnico. A Tabela 9 apresenta a matriz das correlações existentes entre o preconceito racial e o contacto interétnico face aos 3 grupos raciais.

Tabela 9. Correlações entre preconceito e contacto interétnico face aos 3 grupos raciais em função do grupo de autocategorização

\begin{tabular}{lccccccc}
\hline & $\mathbf{1}$ & $\mathbf{2}$ & $\mathbf{3}$ & $\mathbf{4}$ & $\mathbf{5}$ & $\mathbf{6}$ & $\mathbf{7}$ \\
\hline 1. Preconceito M & - & $.79^{* *}$ & $.62^{* *}$ & $-.24^{* *}$ & -.12 & .00 & $-.20^{* *}$ \\
2. Preconceito N & $.70^{* *}$ & - & $.55^{* *}$ & $-.26^{* *}$ & $-.16^{*}$ & .02 & $-.22^{* *}$ \\
3. Preconceito B & $.63^{* *}$ & $.61^{* *}$ & - & $-.28^{* *}$ & -.11 & -.12 & $-.26^{* *}$ \\
4. Contacto Int. M & $.27^{*}$ & .16 & .13 & - & $.30^{* *}$ & .15 & $.75^{* *}$ \\
5. Contacto Int. N & -.16 & .04 & -.09 & .09 & - & $.18^{*}$ & $.74^{* *}$ \\
6. Contacto Int. B & -.02 & -.06 & -.17 & .23 & .15 & - & $.56^{* *}$ \\
7. Total Contacto Int. & .04 & .07 & -.07 & $.65^{* *}$ & $.64^{* *}$ & $.70^{* *}$ & - \\
\hline
\end{tabular}

Nota. Correlações para o Grupo B (n=187) são apresentadas por cima da diagonal e as correlações para o Grupo M (n=71) são apresentados por baixo da diagonal. Nível de significância: ${ }^{* *} p<. .01 ;{ }^{*} p<.05$.

No Grupo B (crianças brancas) verifica-se a existência de correlações negativas fracas entre o contacto interétnico com pessoas mulatas e o preconceito racial face a pessoas mulatas, $r=-.24, p<.01$, e correlações negativas moderadas entre o contacto interétnico com pessoas mulatas e o preconceito face a pessoas negras, $r=-.26, p<.01$ e face a pessoas brancas, $r=-.28, p<.01$. 0 contacto interétnico com pessoas negras correlaciona-se negativamente com o preconceito face a pessoas negras, $r=-.16, p<.05$. Por outro lado, existem correlações negativas fracas entre o contacto interétnico na globalidade e o preconceito face a pessoas mulatas, $r=-.20, p<.01$, pessoas negras, $r=-.22, p<.01$, e pessoas brancas, $r=-.26, p<.01$.

Estes resultados demonstram que, no grupo de crianças brancas, um maior contacto com pessoas mulatas se correlaciona com um menor preconceito face aos 3 grupos raciais, bem como um maior contacto étnico na generalidade; e um maior contacto com pessoas negras se relaciona negativamente apenas com o preconceito em relação a pessoas negras.

Distância Social e Contacto Interétnico. Foram ainda realizadas correlações de Pearson para verificar a existência de correlações entre o contacto interétnico e a distância social, operacionalizada no presente estudo enquanto forma subtil de preconceito racial (Tabela 10). 
Tabela 10. Correlações entre o Contacto Interétnico e a Distância Social face aos 3 grupos raciais em função do grupo de autocategorização

\begin{tabular}{lccccccc}
\hline & $\mathbf{1}$ & $\mathbf{2}$ & $\mathbf{3}$ & $\mathbf{4}$ & $\mathbf{5}$ & $\mathbf{6}$ & $\mathbf{7}$ \\
\hline 1. Contacto Int. M & - & $.30^{* *}$ & .15 & $.75^{* *}$ & $-.33^{* *}$ & $-.17^{*}$ & -.08 \\
2. Contacto Int. N & .09 & - & $.18^{*}$ & $.74^{* *}$ & $-.23^{* *}$ & $-.26^{* *}$ & -.05 \\
3. Contacto Int. B & .23 & .15 & - & $.56^{* *}$ & -.07 & -.01 & -.13 \\
4. Total Contacto Int. & $.65^{* *}$ & $.64^{* *}$ & $.70^{* *}$ & - & $-.32^{* *}$ & $-.23^{* *}$ & -.12 \\
5. Distância Social M & .00 & -.06 & -.17 & -.12 & - & $.63^{* *}$ & $.45^{* *}$ \\
6. Distância Social N & $-.25^{*}$ & $-.27^{*}$ & -.16 & $-.34^{* *}$ & $.36^{* *}$ & - & $.26^{* *}$ \\
7. Distância Social B & .07 & .13 & -.20 & .01 & $.47^{* *}$ & $.24^{*}$ & - \\
\hline
\end{tabular}

Nota. Correlações para o Grupo B (n=187) são apresentadas por cima da diagonal e as correlações para o Grupo M (n=71) são apresentados por baixo da diagonal. Nível de significância: ** $p<. .01 ;{ }^{*} p<.05$.

No Grupo B (crianças brancas) existem correlações negativas moderadas entre o contacto interétnico com pessoas mulatas e a distância social face a pessoas mulatas, $r=-.33, p<.01$, entre o contacto interétnico com pessoas negras a distância social face a pessoas negras, $r=-.26, p<.01$, e entre o contacto interétnico na globalidade e a distância social face a pessoas mulatas, $r=-.32, p<.01$. Por outro lado, existem ainda correlações negativas fracas entre o contacto interétnico com pessoas negras e a distância social face a pessoas mulatas, $r=-.23, p<.01$, e o contacto interétnico com pessoas mulatas, $r=-.17, p<.05$, e a distância social face a pessoas negras e, e a globalidade do contacto interétnico, $r=-.23, p<.01$, e a distância social face a pessoas negras. Quanto ao Grupo M (crianças mulatas), verifica-se a existência de correlações negativas moderadas entre a distância social face a pessoas negras e o contacto interétnico com pessoas mulatas, $r=-.25, p<.05$, negras, $r=-.27, p<.05$, e o contacto interétnico na generalidade, $r=-.34, p<.01$.

0 contacto interétnico correlaciona-se com a distância social: no grupo B um maior contacto na globalidade relaciona-se com uma menor distância social face a $\mathrm{M}$ e N, e um maior contacto com pessoas mulatas e negras com uma menor distância social face a ambos ( $\mathrm{M} \mathrm{e} \mathrm{N}$ ), sendo mais significativo quando a correlação se refere ao mesmo grupo alvo (M-M e N-N); no grupo $\mathrm{M}$, um maior contacto interétnico na globalidade, com pessoas mulatas e negras, relaciona-se de forma negativa com a distância social face ao grupo N.

\section{DISCUSSÃo}

No presente estudo houve a diferenciação propositada entre crianças mulatas e negras, ao contrário da generalidade dos estudos na Europa e Estados Unidos que geralmente envolvem comparações entre dois grupos, nomeadamente brancos e negros (Sacco et al., 2016). Indivíduos birraciais podem não se identificar necessariamente de acordo com o seu fenótipo (uma pessoa birracial pode-se identificar como birracial enquanto fenotipicamente é negra) (Young et al., 2017). Desta forma, a raça ou etnia deve ser obtida por autorrelato, sendo a autocategorização a melhor forma de avaliação da pertença étnica/racial, visto que se relaciona com a perceção individual dessa pertença.

Apesar das pistas visuais aquando a aplicação dos questionários e a própria escolha de locais com maior diversidade étnica, o número de crianças a autocategorizarem-se como negras foi reduzido, o que pode por si só ser indicativo da existência de preconceito/discriminação. Nesse sentido, retrata uma desidentificação psicológica do seu grupo como estratégia de autoproteção contra a discriminação estratégia de mobilidade social (Tajfel, 1974). Tal pode estar associado à identificação com o grupo das crianças mulatas de modo a atenuar a diferença pela aproximação com o grupo mais próximo. Fenómeno idêntico foi verificado por Monteiro (2002) quando constatou que as crianças negras escolhem predominantemente como categorias de pertença os grupos mais claros, o que demonstra "consciência da sua condição de exclusão social na sociedade em que estão a crescer” (Monteiro, 2002, pp.278).

Os estudos de Rodrigues e colaboradores (2010) e Vala e colegas (2015) demonstram que as crianças a partir de uma certa idade não reduzem o preconceito mas começam a modelar a forma como o expressam. Na presente investigação, os reduzidos níveis de preconceito podem-se relacionar com a presença da norma antirracista não só já internalizada, mas duplamente saliente nas turmas pela sua composição étnica; e ainda pelo facto da recolha dos dados ser através de questionário, o que não facilita a expressão do preconceito tradicional pela maior facilidade de controlo das respostas (Vala et al., 2015). 0 número elevado de questionários excluídos por respostas idênticas ("copiadas") nos três grupos alvo de preconceito e Distância Social demonstram o esforço para o controlo das respostas. Por outro lado, é fundamental considerar que a norma social pode estar confinada a um determinado contexto, nomeadamente o da sala de aula onde foi realizado o estudo e não haver, portanto, essa transposição para 
fora da escola ou para o próprio recreio. Poderá, então, ser também a gestão da expressão do preconceito em função do contexto que explica a sua diminuição (França \& Monteiro, 2004).

Os estudos psicométricos revelaram a boa qualidade dos instrumentos, o que permite a utilização do questionário como instrumento de avaliação. A escala de Distância Social ao estruturar-se por grupo racial torna muito clara a pertinência da categorização dos 3 grupos. Quanto à escala do preconceito, os fatores organizam-se considerando os atributos individuais das próprias crianças, o que poderá ter em conta a influência da norma antirracista. No fator 4, que se refere a preconceito mais flagrante (aspetos negativos) divide-se em $\mathrm{N}, \mathrm{M}$ e depois por $\mathrm{B}$, sugerindo que deveria haver mais estudos com outras amostras, nomeadamente crianças $\mathrm{N}$.

Verifica-se que os rapazes apresentam atitudes mais preconceituosas, o que vai de encontro ao estudo de Sarafidou e colaboradores (2014), com participantes entre os 10 e os 13 anos, que verificaram que o preconceito flagrante é mais evidente nos rapazes; o mesmo se verificou no estudo realizado em Portugal por Guinote e colaboradores (2007), que demonstrou que os rapazes percecionam o endogrupo de forma mais variável que o exogrupo (homogeneidade do exogrupo), o que pode por si só ser uma forma de preconceito (Costa-Lopes et al., 2008).

A identidade social é talvez a motivação subjacente que está por trás do preconceito e discriminação (Stangor, 2016). Não existindo uma relação linear entre identidade social e descredibilização ou preconceito face a exogrupos (Brown, 2010; Killen \& Rutland, 2011), o presente estudo pretendia verificar se, na amostra recolhida, existiam diferenças tendo em conta as duas variáveis.

A componente afetiva da identidade étnica, apesar de não evidenciar relação com o preconceito explícito demonstra diferenças no que se refere a forma subtil de preconceito - distância social. No grupo das crianças brancas parece que uma maior identificação se pode relacionar com maiores níveis de distância social face a N e M, ou seja, maiores níveis de preconceito subtil face aos dois exogrupos, o que poderá estar relacionado com a existência no grupo de normas promotoras de exclusão (Nesdale et al., 2010). No grupo das crianças mulatas os resultados parecem enfatizar a existência de uma identidade social comum.

No Grupo M (crianças mulatas) um maior nível de pertença étnica (gosta muito e pretende manterse no seu grupo) está associado a menores níveis de Distância Social face a N. Sendo assim, quanto mais as crianças gostam de ser mulatas (ou "se sentem" mulatas), maior é a intimidade ou proximidade com o seu grupo e o das crianças negras, o que pode fazer subentender que funcionam apenas como um grupo ${ }^{4}$. Os resultados podem dever-se por um lado à desidentificação que pode ter havido das crianças negras para o grupo das crianças mulatas ou, por outro lado, sugerir a existência de uma identidade social comum que aproxima os dois grupos.

Os indícios de uma possível identidade endogrupal comum são suportados pelos resultados da componente afetiva da identidade étnica no que diz respeito à distância social, pela relação entre distância social e preconceito (existe apenas face a B no Grupo M) e pela própria AFE da escala de preconceito racial que separa as crianças mulatas e negras das brancas no fator do preconceito - estes podem, de alguma forma, dar evidência do Modelo de Identidade Endogrupal Comum ${ }^{5}$ (Gaertner \& Dovidio, citado por Monteiro, 2013). 0 preconceito subtil é menor face a $\mathrm{N}$ e $\mathrm{M}$ no grupo $\mathrm{M}$, o que se pode relacionar com a existência de um maior contacto interétnico ou, por outro lado, demonstrar que a possível existência de uma identidade endogrupal comum se pode associar a atitudes mais positivas. Seria, no entanto, fundamental a inclusão do terceiro grupo (crianças $\mathrm{N}$ ) para verificar se os resultados iriam no mesmo sentido.

A Distância Social relaciona-se positivamente com o preconceito, sendo que vai de encontro ao facto de ser operacionalizada enquanto uma forma de expressão subtil/implícita do mesmo (Nesdale et al., 2004).

Quanto ao contacto interétnico, este demonstra-se fundamental na redução do preconceito, tanto subtil como flagrante, visto que na generalidade um maior contacto relaciona-se com um menor preconceito e distância social, principalmente nas crianças do grupo maioritário. Os resultados obtidos vão no mesmo sentido que os estudos que demonstram que o contacto, mesmo superficial ou indireto, tem efeito no preconceito e é, por conseguinte, importante incluí-lo não só na investigação, mas também e principalmente nas estratégicas psicoeducativas e na composição das escolas.

\footnotetext{
${ }^{4}$ A relação entre distância social e preconceito racial nas crianças mulatas também se verifica apenas face ao grupo B (crianças brancas).

5 Modelo que inclui não apenas a eliminação da categorização (focando a individualidade dos seus membros) de modo a diminuir a saliência dos limites intergrupais, mas também a criação de um endogrupo comum (nós) de natureza supra-ordenada ao incluir novos limites mais inclusivos (Monteiro, 2013).
} 


\section{LIMITAÇÕES E ESTUDOS FUTUROS}

Podem-se identificar alguns aspetos que podem ter influenciado os resultados: fatores distratores devido à aplicação ter sido em grupo (haver barulho, os/as participantes falarem entre si, terem receio que os/as colegas pudessem ver as suas respostas, os/as professores/as estarem presentes); e o reduzido número de crianças a autocategorizarem-se como negras que levou à eliminação de um grupo para comparação.

O Questionário de Atitudes e Relações Intergrupais construído para efeito deste estudo avalia mais aspetos explícitos do preconceito; no entanto, atualmente, devido à norma antirracista, a forma de expressão do preconceito passou a ser mais subtil, pelo que se torna necessário no futuro introduzir outras medidas indiretas de preconceito (além da Distância Social), como por exemplo a aplicação do Implicit Association Test em papel.

Quanto à componente afetiva da identidade étnica, a questão referente ao quanto gosta de estar no seu grupo de autocategorização poderia ter tido uma escala de resposta de cinco pontos, ao acrescentar a possibilidade "indiferente" (tendo em conta as estatísticas descritivas da questão). Para além disso, a avaliação emocional da pertença, poderia ter sido medida de forma mais pormenorizada, permitindo assim verificar a importância da pertença e a afetividade.

Tendo em conta os resultados deste estudo, seria pertinente: o estudo dos três grupos "raciais" (brancos, mulatos e negros) de modo a permitir uma melhor compreensão das relações intergrupais existentes; questionar as crianças sobre a sua perceção da heterocategorização, de modo a servir como medida de discrepância em relação à autocategoriação; o estudo comparativo entre locais com e sem contacto interétnico, de modo a verificar como se manifesta o preconceito nos participantes destes dois contextos; considerar outras populações e contextos, como turmas com maioria de crianças ou jovens negros, tendo em conta as implicações da composição étnica das turmas e a alteração do estatuto dos grupos que isso envolve. É pertinente também o desenvolvimento de estudos para validação e aprofundamento do instrumento de avaliação (QARI).

\section{IMPLICAÇõES}

É fundamental ter em conta o contacto interétnico nos contextos educativos e no combate ao preconceito pela sua relação com níveis mais reduzidos de ambas as formas de preconceito racial, e por possibilitar também a identidade endogrupal comum. Desta forma, é importante a criação de programas ou estratégias que promovam o contacto interétnico e as amizades intergrupais, considerando que a diversidade étnica das escolas é crucial no desenvolvimento de atitudes positivas intergrupais (Falanga et al., 2014). A simples existência de contacto tem efeito e verifica-se, através da utilização de programas de intervenção com base na sua promoção, que as atitudes positivas se generalizam também a outros exogrupos (Lemmer \& Wagner, 2015). Não se deve descurar o potencial das formas indiretas de contacto quando o contacto direto não é possível. Desta forma, na globalidade, pode-se considerar sessões de contacto, aprendizagem cooperativa e programas de "extended contact" pelos seus efeitos positivos (Lemmer \& Wagner, 2015).

As estratégias de intervenção a utilizar podem ser variadas, desde a promoção do contacto entre crianças de diferentes grupos, a mudança das normas sociais da escola e a criação de categorias mais inclusivas. Os enviesamentos intergrupais e a identidade étnica começam a desenvolver-se desde muito cedo, devendo, portanto, estes aspetos começar a ser trabalhados precocemente, no sentido da criação de atitudes positivas face a outros grupos, não descurando também a criação de um quadro normativo que condene a discriminação como aspeto que pode ser central (Rodrigues et al., 2010).

Tendo em consideração as evidências empíricas, o presente estudo demonstra principalmente: o efeito do contacto interétnico, sendo fundamental promover oportunidades de amizade; a importância que pode ter a criação de identidades comuns na promoção de relações intergrupais mais positivas; e a importância, nas medidas psicopedagógicas, do reconhecimento dos diferentes grupos étnicos ou raciais (em termos de cultura e da própria existência de preconceito) sem, no entanto, tornar salientes as relações intergrupais.

É fundamental ter ainda em consideração a interseção entre múltiplas identidades grupais marginalizadas (e.g. raça/etnia, estatuto de imigrante/refugiado, estatuto socioeconómico e orientação sexual). Indivíduos que se identificam como membros de um destes grupos experienciam discriminação, sendo que esta aumenta exponencialmente quando essas identidades se intersetam. Desta forma, o foco nas múltiplas dimensões da identidade e o seu potencial para a discriminação permite expandir a capacidade da escola em promover uma educação adequada (National Association of School Psychologists - NASP, 2017). 


\section{REFERÊNCIAS}

Abrams, D., \& Killen, M. (2014). Social exclusion of children: Developmental origins of prejudice. Journal of Social Issues, 70 (1), 1-11. https://doi.org/10.1111/josi.12043

Alamilla, S. G., Kim, B. S. K., Walker, T., \& Sisson, F. R. (2017). Acculturation, enculturation, perceived racism, and psychological symptoms among Asian American college students. Journal of Multicultural Counseling and Development, 45, 37-65. https://doi.org/10.1002/jmcd.12062

Alexandre, J. D., Monteiro, M. B., \& Waldzus, S. (2007). More than comparing with majorities: the importance of alternative comparisons between children from different minority groups. International Journal of Psychology and Psychological Therapy, 7(2), 201-212.

Alfieri, S., \& Marta, E. (2015). Sibling relation, ethnic prejudice, direct and indirect contact: There is a connection?. Europe's Journal of Psychology, 11(4), 664-676. https://doi.org/10.5964/ejop.v11i4.95

Ashmore, R., Deaux, K., \& McLaughlin-Volpe, T. (2004). An organizing framework for collective identity: Articulation and significance of multidimensionality. Psychological Bulletin, 130, 80-114. https://doi.org/10.1037/0033-2909.130.1.80

Bano, S., \& Mishra, R. C. (2014). Development of social identity and prejudice in Hindu and Muslin children. Social Science International, 30(1), 127-142.

Bennet, M., Barrett, M., Karakozov, R., Kipiani, G., Lyons, E., Pavlenko, V., \& Riazanova, T. (2004). Young children's evaluations of the ingroup and of outgroups: A multi-national study. Social Development, 13(1), 124-141. https://doi.org/10.1046/j.1467-9507.2004.00260.x

Berger, R., Benatov, J., Abu-Raiya, H., \& Tadmor, C. T. (2016). Reducing prejudice and promoting positive intergroup attitudes among elementar-school children in the context of the Israeli-Palestinian conflict. Journal of School Psychology, 57, 53-72. https://doi.org/10.1016/j.jsp.2016.04.003.

Brown, R. (2010). Prejudice: Its social psychology. John Wiley \& Sons.

Castelli, L., \& Tomelleri, S. (2008). Contextual effects on prejudiced attitudes: When the presence of others leads to more egalitarian responses. Journal of Experimental Social Psychology, 44, 679-686. https://doi.org/10.1016/j.jesp.2007.04.006.

Clark, K. S., Yovanoff, P., \& Tate, C. U. (2017). Development and psychometric validation of a child Racial Attitudes Index (RAI). Behavior Research Methods, 49, 2044-2060.. https://doi.org/10.3758/s13428-016-0841-y

Collings, D. P. (2006). Selecting a questionnaire response scale for student feedback surveys: A comparison of psychometric properties and student preferences among three alternatives. Murdoch University.

Costa-Lopes, R., Vala, J., Pereira, C., \& Aguiar, P. (2008). A construção social das diferenças nas relações entre grupos sociais. In M. V. Cabral, K. Wall, S. Aboim \& F. Carreira (Eds.), Itinerários: A Investigação nos 25 anos do ICS, (pp. 769 -790). Imprensa de Ciências Sociais.

Dalmoro, M. \& Vieira, K. M. (2013). Dilemas na construção de escalas tipo Likert: o número de itens e a disposição influenciam nos resultados? Revista Gestão Organizacional, 6, 161- 174. https://doi.org/ https://doi.org/10.22277/rgo.v6i3.1386

Dore, R. A., Hoffman, K. M., Lillard, A. S., \& Trawalter, S. (2014). Children's racial bias in perceptions of others' pain. British Journal of Developmental Psychology, 32, 218-231. https://doi.org/10.1111/bjdp.12038

Egito, J. H. T. (2013). The development of racial stereotype in Portuguese children [Dissertação de Mestrado não publicada]. Universidade do Minho.

Falanga, R., De Caroli, M. E., \& Sagone, E. (2014). Subtle and blatant prejudice toward Africans in Italian adolescents. Procedia-Social and Behavioral Sciences, 116, 708-712. https://doi.org/ 10.1016/j.sbspro.2014.01.284

França, D. X., \& Monteiro, M. B. (2002). Identidade racial e preferência em crianças brasileiras de cinco a dez anos. Psicologia, 16 (2), 293-323. https://doi.org/10.17575/rpsicol.v16i2.482

França, D. X., \& Monteiro, M. B. (2004). A expressão das formas indiretas de racismo na infância. Análise Psicológica, 4 (XXII), 705-720.

França, D. X., \& Monteiro, M. B. (2013). Social norms and the expression of prejudice: The development of aversive racism in childhood. European Journal of Social Psychology, 43, 263-271. https://doi.org/10.1002/ejsp.1965

Gaertner, S., Guerra, R., Rebelo, M., Dovidio, J., Hehman, E., \& Deegan, M. (2016). The common ingroup identity model and the development of a functional perspective: A cross-national collaboration. In J. Vala, S. Waldzus \& M. M. Calheiros (Eds.), The social developmental construction of violence and intergroup conflict, (pp. 105-120). Springer. https://doi.org/10.1007/978-3-319-42727-0

Gautier, M. C. P. (2016). Ethnic identity and Latino youth: The current state of the research. Adolescent Research Review, 1, 329-340. https://doi.org/10.1007/s40894-016-0034-z 
Guinote, A., Mouro, C., Pereira, M. H., \& Monteiro, M. B. (2007). Children's perceptions of group variability as a function of status. International Journal of Behavioral Development, 31(2), 97-104. https://doi.org/10.1177/0165025407073930

Keenan, C., Connolly, P., \& Stevenson, C. (2016). PROTOCOL: Universal preschool-and school-based education programmes for reducing ethnic prejudice and promoting respect for diversity among children aged 311: A systematic review and meta-analysis. Campbell Systematic Reviews, 12, 1-45. https://doi.org/10.1002/CL2.164

Killen, M., \& Rutland, A. (2011). Children and social exclusion: Morality, prejudice, and group identity. John Wiley \& Sons.

Lemmer, G., \& Wagner, U. (2015). Can we really reduce ethnic prejudice outside the lab? A meta-analysis of direct and indirect contact interventions. European Journal of Social Psychology, 45, 152-168. https://doi.org/10.1002 /ejsp.2079

Lima, M. E. O., \& Vala, J. (2004). As novas formas de expressão do preconceito e do racismo. Estudos de Psicologia, 9(3), 401-411. https://doi.org/10.1590/S1413-294X2004000300002Marques, J. M., Páez, D. \& Pinto, I. R. (2013). Estereótipos, antecedentes e consequências das crenças sobre os grupos. In J. Vala \& M. B. Monteiro (Coords.), Psicologia social (9å Ed.) (pp.435-492). Fundação Calouste Gulbenkian.

Máximo, T. A. C. O., Larrain, L. F. C. R., Nunes, A. V. L., \& Lins, S. L. B. (2012). Processos de identidade social e exclusão racial na infância. Psicologia em Revista, 18(3), 507-526. https://doi.org/0.5752/P.16789563.2012v18n3p507

Monteiro, M. B. (2002). A construção da exclusão social nas relações interétnicas. Psicologia, XVI(2), 271292. https://doi.org/10.17575/rpsicol.v16i2.481

Monteiro, M. B. (2013). Relações intergrupais. In J. Vala \& M. B. Monteiro (Coord.), Psicologia social (9ª Ed.) (pp. 493-568). Fundação Calouste Gulbenkian.

Monteiro, M. B., França, D. X., \& Rodrigues, R. (2009). The development of intergroup bias in childhood: How social norms can shape children's racial behaviours. International Journal of Psychology, 44(1), 29-39. https://doi.org/10.1080/00207590802057910

Mouro, C., Monteiro, M. B., \& Guinote, A. (2002). Estatuto, identidade étnica e perceção de variabilidade nas crianças. Psicologia, XVI (2), 387-408. https://doi.org/10.17575/rpsicol.v16i2.485

National Association of School Psychologists - NASP (2017). Understanding intersectionality [Handout]. Author

Nesdale, D. (2000). Developmental changes in children's ethnic preferences and social cognitions. Journal of Applied Developmental Psychology, 20(4), 501-519. https://doi.org/10.1016/S01933973(99)00012-X

Nesdale, D., Durkin, K., Maass A., \& Griffiths, J. (2004). Group status, outgroup ethnicity and children's ethnic

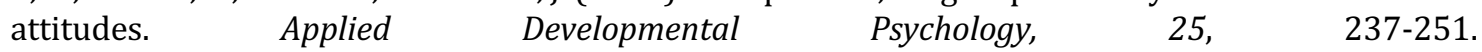
https://doi.org/10.1016/j.appdev.2004.02.005

Nesdale, D., Durkin, K., Maass, A., Kiesner, J., Griffiths, J., Daly, J., \& McKensie, D. (2010). Peer group rejection and children's outgroup prejudice. Journal of Applied Developmental Psychology, 31, 134-144. https://doi.org/10.1016/ j.appdev.2009.11.004

Pettigrew, T. F., \& Tropp, L. R. (2006). A meta-analytic test of intergroup contact theory. Journal of Personality and Social Psychology, 90, 751-783. d https://doi.org/10.1037/0022-3514.90.5.751.

Raabe, T., \& Beelmann, A. (2011). Development of ethnic, racial, and national prejudice in childhood and adolescence: A multinational meta-analysis of age differences. Child Development, 82(6), 1715-1737. https://doi.org/10.1111/j.1467-8624.2011.01668.x

Rodrigues, R. B., Monteiro, M. B., \& Rutland, A. (2010). Cada cabeça, duas sentenças: aprendizagem e ativação das normas anti-racista e do favoritismo endogrupal ao longo da infância e avaliações interraciais em crianças de brancas de origem lusa. In C. Nogueira, I. Silva, L. Lima, A. T. Almeida, R. Cabecinhas, R. Gomes, C. Machado, A. Maia, A. Sampaio \& M. C. Taveira (Eds.), Actas do VII Simpósio Nacional de Investigação em Psicologia (pp. 3459 -3470). Universidade do Minho.

Rutland, A., Brown, R., Cameron, L., Ahmavaara, A., Arnold, K., \& Samson, J. (2007). Development of the positive-negative asymmetry effect: Ingroup exclusion norm as mediator of children's evaluations on negative attributes. European Journal of Social Psychology, 37, 171- 190. https://doi.org/ $10.1002 /$ ejsp.342

Sacco, A. M., Couto, M. C. P. P., \& Koller, S. H. (2016). Revisão sistemática de estudos da psicologia brasileira sobre preconceito racial. Temas em Psicologia, 24(1), 233-250. https://doi.org/10.9788/TP2016.116 
Sarafidou, J., Govaris, C., \& Loumakou, M. (2014). The subtle-blatant distinction of ethnic prejudice among ethnic majority children. Intercultural Education, 24(3), 264-276. https://doi.org/10.1080/14675986.2013.799805.

Stangor, C. (2016). The study of stereotyping, prejudice, and discrimination within Social Psychology. In T. D. Nelson (Ed.), Handbook of prejudice, stereotyping, and discrimination (pp. 3-27). Psychology Press. Tabachnick, B. G., \& Fidell, L. S. (2013). Using multivariate statistics (6 ${ }^{\underline{a}}$ Ed.). Pearson.

Tajfel, H. (1974). Social identity and intergroup behavior. Social Science Information, 13(2), 65-93. https://doi.org/10.1177/053901847401300204

Tajfel, H. (1982). Social psychology of intergroup relations. Annual Review of Psychology, 33, 1-39. https://doi.org/10.1146/annurev.ps.33.020182.000245

Tajfel, H. \& Turner, J. C. (1986). The social identity theory of intergroup behavior. In S. Worchel, W. Austin (Eds), Psychology of intergroup relations (pp. 7-24). Nelson Hall.

Tredoux, C., \& Finchilescu, G. (2010). Mediators of the contact-prejudice relation among South African students on four university campuses. Journal of Social Issues, 66(2), 289-308. https://doi.org/10.1111/j.1540-4560.2010.01646.x

Vala, J., \& Costa-Lopes, R. (2016). Categorização social e fatores ideológicos na dinâmica das relações intergrupais. In D. X. França, M. E. Lima (eds), Níveis de análise e formas de intervenção em psicologia social, (pp.43-73). Scortecci.

Vala, J., Brito, R., \& Lopes, D. (2015). Expressões dos racismos em Portugal (2ª Ed. Online). Imprensa de Ciências Sociais.

Young, D. M., Sanchez, D. T., \& Wilton, L. S. (2017). Biracial perception in black and white: how black and white perceivers respond to phenotype and racial identity cues. Cultural Diversity and Ethnic Minority Psychology, 23(1), 154-164. https://doi.org/10.1037/cdp0000103

$\begin{array}{lr}\text { Historial do artigo } \\ \text { Recebido } & 05 / 2018 \\ \text { Aceite } & 07 / 2020 \\ \text { Publicado } & 12 / 2020\end{array}$

